\title{
Voluntary counseling and testing utilization and associated factors among teachers in Arsi Negele district,West Arsi zone, Oromia regional state, Ethiopia
}

\begin{abstract}
Background: Human immune virus is affecting most productive segments of the population that form the basic education sector which is vital to the creation of human capital. The loss of skilled and experienced teachers due to the problem is increasingly compromising the provision of comprehensive and quality education in most African countries.
\end{abstract}

Objective: The aim of this study is to assess the magnitude and factors associated with Voluntary counseling testing service utilization for HIV/AIDS among teachers working in Arsi Negele district, West Arsi Zone, Oromia Region, Ethiopia.

Methods: Institution based cross sectional study design was done among 737 teachers drawn from 32 randomly selected schools in Arsi Negele district, Oromia Region. Self-administered questionnaire was used to estimate the magnitude of voluntary counseling and testing service utilization for HIV/AIDS and explore factors associated with it .Data were entered, cleaned and analyzed using SPSS version 16. Multivariable logistic regression was done. The results were displayed by numerical summery measures, graphs and tables.

Result: A total number of 681 teachers responded to the questionnaire making the response rate of $92.4 \%$. The mean age of the study participants was 29.58 with standard deviation of 8.44 . Most of respondents were males(73.3\%) and single $(50.7 \%)$ The magnitude of VCT service uptake in the current study is $58.7 \%$. Age category [AOR: 1.999, 95\% CI: $(1.174,3.405)]$, teachers' category [AOR: 2.066, 95\% CI:(1.080, $3.953)$ ], perceived stigma and discrimination [AOR: $2.483,95 \% \mathrm{CI}:(1.455,4.235)]$ and knowing the availability of ART in the VCT sites [AOR: 3.373, 95\%CI:(1.935, 5.819)] were found to be significantly associated with VCT service utilization by teachers.

Conclusion: Higher prevalence of VCT uptake was observed in this study. The major predicting variables of VCT utilization by teachers identified were age category, teachers' category, perceived stigma and discrimination and knowing the availability of ART in the VCT sites.

Keywords: voluntary counseling and testing, utilization, teachers, Arsi Negele
Volume 6 Issue 3 - 2017

\author{
Rameto Aman Nuri \\ Department of Public health, Madda Walabu University, Ethiopia
}

Correspondence: Rameto Aman Nuri, Department of Public Health, Goba referral hospital, Madda Walabu University, BaleGoba, Ethiopia, Tel +251912153792, Email rametoaman@gmail.com

Received: July 21, 2017 | Published: August 31, 2017
Abbreviations: AIDS, acquired immuno-deficiency syndrome; AOR, adjusted odds ratio; ART, anti-retroviral therapy; CI, confidence interval; COR, crude odds ratio; HIV, human immuno-deficiency virus; NGO, non-governmental organization; OR, odds ratio; PLWH, people living with HIV; PMTCT, prevention mother- to- child transmission; VCT, voluntary counseling and testing; WHO, world health organization

\section{Introduction}

The impact of HIV/AIDS goes beyond public health concerns as it undermines the social and economic structures particularly that of developing countries. On the basis of the report at the end of 2008, 33.4Millions of people live with HIV/AIDS, 2.7 Million people newly infected with HIV and two Millions AIDS death were estimated in the world. ${ }^{1-3}$ The magnitude of HIV/AIDS among teachers was also known to be high in Africa countries. In 2003 in Kenya 6.6\%, in 2005 in Rwanda \& Ethiopia $3.25 \%$ \& $1.92 \%$ respectively and in Tanzania
$6.47 \%$ teachers were known to be infected with the Human Immuno virus. ${ }^{4}$ In Ethiopia, the national adult(ages 15-49) HIV prevalence for 2008 was estimated to be $2.2 \%$ with an urban and rural HIV prevalence of $7.7 \%$ and $0.9 \%$ respectively. ${ }^{5}$ The relationship between AIDS and the education sector is circular as the epidemic get worse; the education sector will be damaged, which in turn likely increase the incidence of HIV transmission. There are numerous ways in which AIDS can affect education, but equally there are many ways in which education can help the fight against AIDS. ${ }^{6}$

The pandemic is affecting most productive segments of the population that form the basic education sector which is vital to the creation of human capital for next generation. The provision of quality education in most African countries is highly in trouble due to the loss of skilled and experienced educators as a result of due to HIV/AIDSrelated long-term morbidity and mortality. ${ }^{7,8}$ The problem is creating a double burden on educational sectors as it has a devastating effect on the already inadequate supply of teachers in most African countries. 
A study in South Africa found that 21\% of teachers aged 25-34 were living with the virus. The morbidity and mortality of teachers are especially shocking in the rural part of developing countries where a majority of schools depend heavily on one or two teachers. ${ }^{9}$

In Ethiopia, the situation is even worse based on the evidence obtained from teachers in Addis Ababa which showed HIV/AIDS related illnesses were the leading cause of death compared with other causes. The Ethiopian Federal Government, in partnership with international and national organizations has invested huge human, financial, and material resources to prevent the spread of HIV and mitigate its impact to PLWH and their immediate families as the number of facilities with ART, prevention of mother-to-child HIV transmission(PMTCT) services and HIV counseling and testing is increasing from time to time. ${ }^{10,11}$

Voluntary counseling and testing is an effective strategy for facilitating behavior change for both clients that test negative and positive. Different studies have shown the effects of VCT including a decrease in unprotected sexual intercourse, a reduction in multiple partners, an increase in condom use, and more clients choosing abstinence. In addition, VCT is an important entry point to other HIV/AIDS services, including prevention of mother to child transmission(PMTCT), prevention and management of HIV related illnesses, and social support for seropositive clients. ${ }^{12}$ In contrary to high levels benefits of voluntary counseling and testing service and global and national responses towards HIV/AIDS, VCT utilization was low particularly among teachers, young and economically active segment of the populations. ${ }^{5}$ Although some information on HIV/AIDS and factors affecting uptake of VCT on different target groups are available, there is scarcity of information on teachers in this regard. Thus, this study is intended to estimate the magnitude and factors associated with utilization of VCT services for HIV/AIDS among teachers working in Arsi Negele district which can be used by police makers to design and implement appropriate intervention strategies that could overcome those barriers for accessing the service.

\section{Materials and methods}

\section{Study design and period}

Institution based cross quantitative sectional study design was conducted among teachers working in Arsi Negele district during September-October 2010.

\section{Study setting}

The study was conducted in Arsi Negele district. Arsi Negele district is located in the Central Rift Valley of Ethiopia in west Arsi Zone, Oromia Region 230 Kilometers from Addis Ababa. ${ }^{13}$ Based on the projection of figures published by the central statistical agency in 2005 , the district has an estimated total population of 198,307 , of whom 100,626 are men and $21.21 \%$ of its population is urban dwellers, with an estimated area of $1,400.16$ square kilometers. ${ }^{14}$ The health system of the district consist of four health centers, 47 health posts, seven private drug vendor, four medium and one higher private clinics and the health coverage of the district is $80 \%$. There are four functional voluntary counseling and testing sites. In the district mobile voluntary counseling and testing services also given for the community.

\section{Source and study population}

The source population was all teachers working in the Arsi Negele district while the study population is all teachers in the selected schools in the district.

i. Inclusion criteria: Teachers working in that district was included.

ii. Exclusion criteria: Severely ill \& blind teachers were excluded.

\section{Sample size determination}

The sample size was determined by using single population proportion formula by taking prevalence of voluntary counseling and testing utilization of $46.3 \%$ which obtained from research conducted among teachers in the Harare administrative zone. ${ }^{15}$ Taking $95 \%$ confidence interval, $5 \%$ tolerable error, correction formula, and design effect of two resulted 737 final sample sizes.

\section{Sampling procedure}

The total numbers of schools and teachers in the district were 105 and 2720 respectively. Of the 105 schools, 40 were urban, and 65 were rural. Taking the average number of teachers in urban and rural schools into consideration, eleven schools from urban and twenty-one from rural schools were selected by simple random sampling technique using lottery method. The total sample size was proportionally allocated to each selected schools, and simple random sampling technique was used to select those teachers included in the study.

\section{Data collection procedure}

Structured and pre-tested self-administered questionnaire adapted from similar previous studies and sample of the questionnaire that was modified to this study setting that translated into both Amharic and Afan Oromo language was used to collect relevant information to achieve the stated research objective. The Questionnaire contains information concerning socio-demographic characteristics, knowledge about HIV/AIDS, attitude toward VCT services, ever used VCT services for HIV/AIDS, perceived benefits and barriers for VCT service uptake, perceived HIV susceptibility, anticipation of HIV/AIDS related stigma and others. Four diploma nurses and one supervisor (B.Sc. nurse) were involved in the pre-testing of the questionnaire and collection of the actual data.

\section{Data quality assurance}

The English version questionnaire was translated into Amharic and Afan Oromo language and back translated to English to check its consistency by respective language expert. The data collectors as well as supervisor were trained for one day on issue related to the objective of the research and overall data collection procedure. Pre -test of the questionnaire on $10 \%$ of teachers other than the selected schools was done to check acceptability as well as consistency and necessary correction was done before the actual data collection. Further supervision by the principal investigator was made as per needed. The completeness of the questionnaire was checked frequently by supervisors and principal investigator.

\section{Data processing and analysis}

The collected data was cleaned, coded, entered and analyzed using SPSS computer software package version 16. Summary statistic of socio-demographic variables is presented using frequencies tables and graphs. Bivariable logistic regression was done to check the association between the outcome variable and each predictor's variables. Multivariable logistic regression analysis was performed 
to assess the association between VCT utilization and various explanatory variables. A p-value less than or equal to 0.05 was taken as the cut of value to be significant. Crude and adjusted Odds ratio and $95 \%$ confidence intervals were constructed along with the corresponding $\mathrm{p}$-value.

\section{Ethical consideration}

Ethical approval was obtained from the ethical review committee of the school of public Health, College of medicine and health sciences, University of Gondar. A written ethical approval was also obtained from Arsi Negele district education office. Informed written consent was secured from each school principal and respective teachers for their participation after the nature of the study was fully explained in their local languages as it was attached in the questionnaire. The right to refuse was respected, and the information collected from the teachers was kept confidential, and the collected information was stored in a file without the name of the study participant. Instead, a code was assigned to it and was not revealed to anyone except the principal investigator and was kept locked with a key.

\section{Results}

From the total of 737 teachers recruited, 681 completed the questionnaire adequately making the response rate of $92.7 \%$. The mean age of the teachers was 29.58 with a standard deviation of 8.44.The number of teachers from urban encompasses $374(54.9 \%)$. About 486(73.3\%) and 345(50.7\%) of teachers were male and single respectively. Around 313(46.0\%) of teachers had a diploma, and $325(47.7 \%)$ were orthodox Christian religion followers. Four hundred fifty-one $(66.2 \%)$ teachers belong to Oromo ethnic group (Table 1) (Figure 1). Study participants were compared to reported reasons for not utilizing voluntary counseling and testing (VCT) service for HIV/AIDS. Accordingly, trusting themselves and their partners were reported by $72(25.6 \%)$ of teachers. About $39(13.9 \%)$ were reported that unwilling to utilize VCT service due to lack of considering themselves as being at risk. Fear of stigma and discrimination associated with positive test result was reported by $115(40.9 \%)$ of teachers as a reason for not utilizing voluntary counseling and testing(VCT) service. Teachers who reported unavailability of the service nearby and considering the service as if it is not useful were account for 45(16.0) and 10(3.6) respectively (Figure 2). Age was significantly associated with VCT uptake by the teachers. Teachers in the age group between 15-35 were more likely to utilize VCT service as compared to those teachers belong to age group above 35years [AOR: 1.999, 95\%CI:(1.174,3.405)]. Knowing availability of ART in the VCT site was found to be significantly associated with VCT service utilization by study participants. Teachers who knew the availability of ART in the VCT site were more likely to utilize VCT service as compared to those did not know [AOR: 3.373 , 95\% CI: $(1.935,5.819)]$. The odds of utilizing of VCT services for HIV/ AIDS was found to be higher to statistical significant among teachers those prefer secret letter way to get HIV test result as compared to those prefer face to face way [AOR: 2.042, 95\% CI:(1.211, 3.442)]. Teachers who did not perceive stigma and discrimination associated with the HIV/AIDS test result were more likely utilize VCT service as compared to their counterpart [AOR: $2.483,95 \% \mathrm{CI}:(1.455,4.235)]$. The odds of VCT uptake were higher among teachers who have one sexual partner [AOR: 1.837, 95\%CI: $(1.005,3.359)]$. Teachers who teach in secondary and preparatory school were 2.066 times more likely utilize VCT service as compared to those taught in the primary and secondary cycle (Table 2 ).
Table I Socio demographic characteristics of study participants, Arsi Negele district, Oromia Regional state, Ethiopia

\begin{tabular}{|c|c|c|}
\hline $\begin{array}{l}\text { Socio-demographic } \\
\text { characteristics }\end{array}$ & Frequency & Relative Frequency \\
\hline \multicolumn{3}{|l|}{ Residence } \\
\hline Urban & 386 & 56.7 \\
\hline Rural & 295 & 43.3 \\
\hline \multicolumn{3}{|l|}{ Sex } \\
\hline Male & 486 & 71.4 \\
\hline Female & 195 & 28.6 \\
\hline \multicolumn{3}{|l|}{ Age category } \\
\hline $15-24$ & 223 & 32.7 \\
\hline $25-34$ & 312 & 45.8 \\
\hline $35-44$ & 92 & 13.5 \\
\hline$>=45$ & 54 & 7.9 \\
\hline \multicolumn{3}{|l|}{ Educational status } \\
\hline Certificate & 169 & 24.8 \\
\hline Diploma & 313 & 46 \\
\hline Degree & 199 & 29.2 \\
\hline \multicolumn{3}{|l|}{ Marital status } \\
\hline Single & 345 & 50.7 \\
\hline Married & 299 & 43.9 \\
\hline Divorced/separated & 22 & 3.2 \\
\hline widowed & 15 & 2.2 \\
\hline \multicolumn{3}{|l|}{ Religion } \\
\hline Orthodox & 325 & 47.7 \\
\hline Muslim & 166 & 24.4 \\
\hline Protestant & 137 & 20.1 \\
\hline Others & 53 & 7.8 \\
\hline \multicolumn{3}{|l|}{ Ethnicity } \\
\hline Oromo & 451 & 66.2 \\
\hline Amhara & 156 & 22.9 \\
\hline Gurage & 43 & 6.3 \\
\hline Kembata & 21 & 3.1 \\
\hline Other & 10 & 1.5 \\
\hline
\end{tabular}

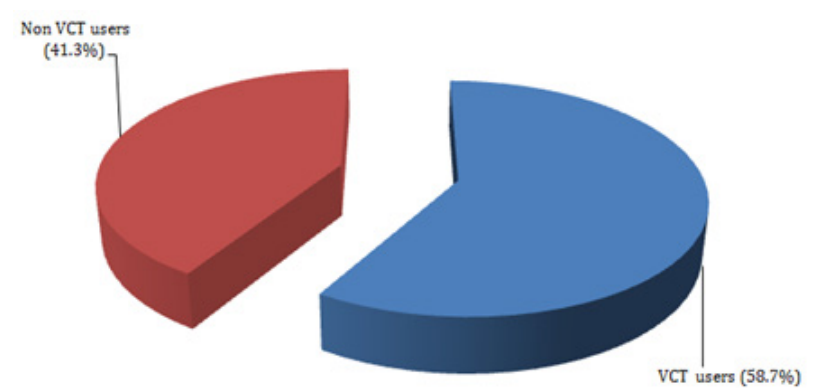

Figure I Magnitude of voluntary counseling and testing service utilization by teachers Arsi Negele woredas, Oromia regional state, Ethiopia. 
Table 2 Factors associated with VCT uptake by teachers in Arsi Negele district, Oromia Regional state, Ethiopia

\begin{tabular}{|c|c|c|c|c|c|}
\hline \multirow[b]{2}{*}{ Variables } & \multicolumn{3}{|c|}{ VCT Uptake } & \multirow[b]{2}{*}{$\operatorname{AOR}(95 \% \mathrm{Cl})$} & \multirow[b]{2}{*}{ P-value } \\
\hline & Yes & No & Crude OR (95\%Cl) & & \\
\hline \multicolumn{6}{|l|}{ Age category } \\
\hline $15-35$ & 263 & 204 & $1.38(0.988,1.927)$ & $1.999(1.174,3.405)$ & 0.011 \\
\hline$>35$ & 137 & 77 & 1 & I & \\
\hline \multicolumn{6}{|l|}{ Teachers category } \\
\hline Primary and secondary cycle & 292 & 210 & 1 & 1 & \\
\hline Secondary and preparatory & 108 & 71 & $0.914(0.645,1.295)$ & $2.066(1.080,3.953)$ & 0.028 \\
\hline \multicolumn{6}{|c|}{ Preference ways of getting HIV test result } \\
\hline Face to face & 256 & 132 & I & I & \\
\hline Secret letter & 129 & $|3|$ & $1.969(1.428,2.716)$ & $2.042(1.211,3.442)$ & 0.027 \\
\hline other & 15 & 18 & $2.327(1.137,4.765)$ & I.8I8(0.264,12.523) & 0.544 \\
\hline \multicolumn{6}{|l|}{ Number of sexual partner } \\
\hline One & 126 & 92 & $1.344(0.921,1.963)$ & $1.837(1.005,3.359)$ & 0.048 \\
\hline Greater than one & 109 & 107 & I & I & \\
\hline \multicolumn{6}{|l|}{ Age of first sex } \\
\hline $14-19$ & 84 & 48 & 1 & I & \\
\hline $20-25$ & 125 & 129 & $1.806(I . \mid 73,2.78 I)$ & $3.254(1.852,5.715)$ & 0 \\
\hline $26-31$ & 26 & 23 & I.548(0.797,3.006) & $8.135(3.063,21.607)$ & 0 \\
\hline \multicolumn{6}{|c|}{ Knowing availability of ART in the VCT site } \\
\hline Yes & 205 & 197 & $2.23 I(1.617,3.078)$ & $3.373(1.935,5.819)$ & 0 \\
\hline No & 195 & 84 & I & I & \\
\hline \multicolumn{6}{|l|}{ Perceived stigma } \\
\hline Yes & 302 & 193 & I & I & \\
\hline No & 97 & 88 & $1.424(1.013,2.002)$ & $2.483(1.455,4.235)$ & 0.001 \\
\hline
\end{tabular}

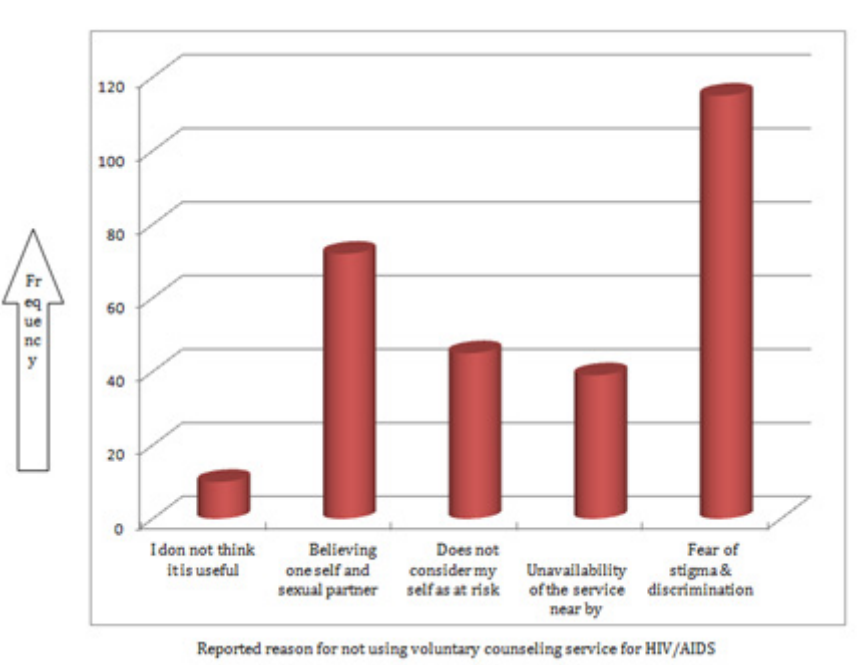

Figure 2 Reason given by the teachers for not using voluntary counseling service Arsi Negele district, Oromia regional state, Ethiopia.

\section{Discussion}

Voluntary counseling and testing(VCT) is proven to be one of the most powerful weapons in halting the spread of HIV/AIDS. It is known to be a very important component of HIV/AIDS prevention strategies. Despite that varies study has shown that low utilization of VCT service particularly in developing countries ${ }^{16}$ This study tried to look into the level and factors associated with VCT utilization by teachers working in Arsi Negele woreda, Oromia region. The overall magnitude of VCT uptake in this study is $400(58.7 \%)$ with slightly higher utilization by females as compared to males. When this result is compared with research done in Mwanza, Tanzania that revealed voluntary counseling and testing uptake of $20 \%$ among primary school teachers and with the research in Kenya that resulted from HIV-VCT utilization among secondary school teachers of $30.5 \%,{ }^{4-17}$ it is higher. It is also higher than the study conducted among teachers in the Harare administration region that revealed the overall prevalence of VCT uptake of $46.3 \%$ and the study in Debre Birhan teachers training college where 35.19 $\%$ of the respondents have ever been tested for HIV/AIDS. ${ }^{15-18}$ The possible reason for this could be a time gap between the studies, the 
difference in composition of the study participant, socio-demographic variation. Also, recent accelerated expansion of the VCT service carried out through an increased advocacy and social mobilization in the region as well as country-wide. ${ }^{19}$ According to this study, $99.7 \%$ of respondents heard about the availability of confidential VCT Services and their major primary sources identified were mass media and health worker which is comparable with the finding from the study conducted among teachers in the Harare administration region that revealed $489(98.4 \%)$ of teachers knew the existence of confidential VCT Service. ${ }^{15}$ But it is higher when compared with the result obtained from the community-based study done among aged 15 to 49 years population in northwest Ethiopia which is $73.5 \%{ }^{20}$ This difference might be due to the difference in the composition of the study participants. The participants in this study were teachers as they were more likely to have access to mass- media that possibly increase their awareness about HIV/AIDS risk and prevention methods. ${ }^{21}$ Regarding knowledge about HIV/AIDS, of the 681 teachers, $668(98.1 \%)$ of them were knowledgeable about HIV/AIDS. However, despite the improved knowledge about HIV/AIDS as a result of the advocacy work, knowledge was not significantly associated with utilization of VCT service by teachers suggesting that knowledge about HIV/AIDS alone does not necessarily guarantee to bring the desired change regarding the issue. This result was supported by the study conducted among teachers in Harare administrative region. ${ }^{15}$ The major reason for the utilization of VCT service was voluntarily followed by for marriage which is consistent with the result of another study in Ethiopia. ${ }^{22}$ Teacher's category was found to be significantly associated with VCT utilization. The odds of VCT uptake increase by being teaching in secondary and preparatory school [AOR: 2.066, $95 \% \mathrm{CI}:(1.080,3.953)]$. This could be because teachers teaching in high school and preparatory are more likely to have better access to VCT service as well as media. This is in line with the result of the study among teacher in the Harare administrative zone. ${ }^{15}$

Being in age group less than 35years was positively associated with the uptake of VCT service [AOR: 1.999, 95\%CI:(1.174, 3.405)]. The possible reason could be such age category is more eager to know their HIV sero-status than older age group. Furthermore, this age category is young and is more likely to be tested for HIV before marriage. This result was also supported by some studies conducted in Ethiopia, Tanzania, and United States of America and Kenya. ${ }^{15-24}$ In this study, sex was not found to be significantly associated with VCT service utilization which contradicts with the result of the study conducted among teachers in Harare Administrative region and that of the study conducted by governmental and non-governmental employee in Butajira. ${ }^{15}$ A possible reason could be recent accelerated expansion of the VCT service carried out through an increased advocacy targeting both sexes. Age at first sexual intercourse was significantly linked with the uptake of VCT service. Teachers started sexual intercourse at the age of 20-25years were 3.3 more likely utilize VCT service as compared to those started below ninety years [AOR: 3.254, 95\% CI:(1.852,5.715)]. This could be because starting sexual intercourse at early age possibly increase sexual exposure which further increases the fear of being having the disease that possible hinder them to utilize VCT service. This research also identified that number of sexual partners to be a significant determinant of the outcome variable. Having a single sexual partner will increase the odds of VCT uptake by 1.8 times as compared to having multiple sexual partners [AOR: 1.837, 955CI: $(1.005,3.359)]$. This could be explained by having multiple sexual partners possibly increase fear of having HIV/AIDS which inurn decrease the utilization of VCT service that may link with fear of coping with the positive test result.

The other finding of this study was the positive association of knowing the availability of ART in the VCT site and uptake of VCT service among teachers. Teachers who knew the availability of ART in the VCT site are 3.373 times more likely to utilize VCT service as compared with those did not know [AOR: 3.373 , 95\% CI:(1.935, 5.819)]. This result was supported by the result of the study conducted in Gondar Administrative zones different professional and community groups. ${ }^{25}$ In this study perceived stigma and discrimination associated with the positive test result was found to be an important determinant of VCT service utilization. Teachers who don't perceive stigma and discrimination were 2.5 times more likely utilize VCT service as compared to their counterpart [AOR: 2.483, 95\% CI:( 1.455, 4.235)]. It is in line with Study conducted in United States of America and among Patients with Tuberculosis in North West Ethiopia where perceived stigma and discrimination was known to be a strong predictor of voluntary counseling and testing service utilization. ${ }^{24-26}$ This study also demonstrated that preference way of getting HIV/ AIDS test result was statistically associated with utilization of VCT service. Teachers who prefer a secretive letter way to get HIV/AIDS test result were more likely utilize VCT service as compared to those prefer face to face way [AOR: $2.042,95 \% \mathrm{CI}:(1.211,3.442)]$. This result was supported by the result of the study in Gurage zone among the general population. ${ }^{27}$

\section{Conclusion}

The overall magnitude of voluntary counseling and testing service utilization for HIV/AIDS in this study is higher when compared with other findings. Age category, teachers category, the number of sexual partners, perceived stigma and discrimination, preference way of getting HIV/AIDS test result, the age of first sex and knowing availability of ART drug in VCT site were identified to be significantly associated with VCT service utilization by teachers. The two main reasons mentioned by study participant for not using VCT service were fear of stigma and discrimination associated with positive test result and Trusting one self and sexual partner.

\section{Recommendation}

Arsi Negele district health office in collaboration with zonal heath office should create continued effort to maximize voluntary counseling and testing utilization by older age group teachers, those don't know availability of ART drug in the VCT site and lower school teachers with proper and tailored information dissemination related to HIV/ AIDS and VCT service in order to achieve the goal of education. The regional health bureau in collaboration with the federal ministry of health should establish appropriate and sustainable activities to bring behavior change of teachers regarding stigma and discrimination associated with HIV/AIDS positive test result, awareness of HIV/ AIDS and VCT service.

\section{Author's contributions}

The overall activity which includes conducting the research till to preparing the manuscript for publication was undertaken by the Rameto Aman author.

\section{Acknowledgments}

I would like to thank all the teachers who participated in this study as well as Arsi Negele education office for their great help for the 
success of this work. My gratitude extends to Azemeraw Tayelegn, Ayala Kembo, Wayu Bedaso, Bokona, Bekana Kebede, Gebra Hemba and Measho G/Sillassie for their great help during the process. I am very grateful to the school of public health, University of Gondar for material and financial support. The last but not the least I would like to thank Bole Bible Baptist(NGO) for material support.

\section{Conflict of interest}

The author declares that there is no conflict of interest with this research article.

\section{References}

1. Kallings LO. The first postmodern pandemic: 25years of HIV/AIDS. $J$ Intern Med. 2008;263(3):218-243.

2. Ministry of Health. National Guidelines for Voluntary HIV Counseling and Testing in Ethiopia. Ethiopia; 2000. p. 1-50.

3. Report on the global AIDS epidemic. Switzerland; UNAIDS. 2008. p. $1-362$.

4. Estimates of the impact of HIV/AIDS \& teachers ART take upon the education sectors and achievement of EFA. 2009.

5. Federal Ministry of Health and Federal HIV/AIDS Prevention and Control Office. Guidelines for HIV Counselling and Testing in Ethiopia. Africa; 2007:1-50.

6. World Bank, UNESCO and UNAIDS Press release. In turning the tide against HIV/AIDS, education is key. 2002.

7. Bakilana A, Bundy D, Brown J, et al. Accelerating the Education Sector Response to HIV/AIDS in Africa: A review of World Bank assistance. World Bank global HIV/AIDS program discussion paper. Africa; 2005:1-44.

8. Bennell P, Hyde K, Swainson N. Impact of the HIV/AIDS Epidemic on the Education Sector in Sub-Saharan Africa: a synthesis of the findings and recommendations of three Country studies. centre for international education. Africa; 2002. p. 1-160.

9. UNAIDS. Report on the global AIDS epidemic. Chapter 4: The impact of AIDS on people and societies. Switzerland; 2006. p. 1-629.

10. Asmelash A. Assessment of HIV/AIDS-Related Mortality among Primary and Secondary School Teachers in Addis Ababa (1998-2003) Using Verbal Autopsy. Ethiopia; 2004:1-91.

11. FMOH and FHAPCO Monthly update. 2008.

12. IPPF South Asia Regional Office and UNFPA. Integrating HIV voluntary counseling and testing services into reproductive health settings stepwise guidelines for programme planners, managers and service providers. 2004:1-87.
13. Socio-economic profile of East Shewa Government of Oromia Region 2010.

14. CSA 2005 national statistics. 2010

15. Shemshedin O, Jemal H. VCT uptake and associated factors among teachers from Harari Administrative Region. Ethiop $J$ Health Dev. 2009;23(3).

16. McCauley A, Edward kirumira. VCT will it attract youth? Horizons, USA; 2004:1-8.

17. Deodatus Conatus Vitalis, Kakoko. Voluntary HIV counseling and testing service uptake and assessment of socio-demographic, psychosocial and socio-cognitive aspects among primary school teachers in Mwanza, Tanzania; 2006

18. Zeytu G. Knowledge, attitude towards practicing of voluntary HIV counseling and testing and the determinants of VCT uptake: a case study in Debre Birhan teachers training college. Ethiopia; 2007:1-79.

19. Yemane Berhane, Yared Mekonnen, Eleni Seyoum, et al. HIV/AIDS in Ethiopia: an epidemiological synthesis. The global HIV/AIDS program. 2008. p. $1-109$

20. Alemu S, Abseno N, Degu G, et al. Knowledge and attitude towards voluntary counseling and testing for HIV: A community-based study in northwest Ethiopia. Ethiop J Health Dev. 2004;18(2):82-89.

21. Kloos H, Wuhib W, Haile Mariam D, et al. Community-based organizations in HIV/AIDS: Lessons Learned from Community-based operations. Ethiop J Health Dev. 2003;17(1).

22. Mulugeta W. Assessment of VCT utilization for HIV/AIDS among government and non-government employees in Butajira, SNNPR, Ethiopia. 2007:1-71.

23. UNAIDS Technical update. Voluntary Counselling Test. Geneva; 2000:1-12.

24. Marita EO, Keraka MN, Mwanzo I. Determinants of HIV-VCT utilization among secondary school teachers in Thika district, Kenya East Afr J Public Health. 2011;8(4):258-262.

25. Mengesha A, Yohannis Fitaw. Factors affecting acceptance of VCT among different professional and community groups in North and South Gondar Administrative zones North West. Ethiopia J Health Dev. 2006:20(1):24-31.

26. Ayenew A, Leykun A, Colebunders R, et al. Predictors of HIV Testing among Patients with Tuberculosis in North West Ethiopia: A CaseControl Study. PLoS One. 2010;5(3):e9702.

27. Getachew W. Factors associated with VCT utilization in Guraghe zone, Snnpr, Ethiopia. 2004:1-92. 